\title{
Electromagnetic navigation bronchoscopy to access lung lesions in 1,000 subjects: first results of the prospective, multicenter NAVIGATE study
}

Sandeep J. Khandhar ${ }^{1 \dagger}$, Mark R. Bowling ${ }^{2}$, Javier Flandes ${ }^{3}$, Thomas R. Gildea ${ }^{4}$, Kristin L. Hood ${ }^{5}$, William S. Krimsky ${ }^{6}$, Douglas J. Minnich ${ }^{714}$, Septimiu D. Murgu ${ }^{8}$, Michael Pritchett ${ }^{9}$, Eric M. Toloza ${ }^{10,11}$, Momen M. Wahidi ${ }^{12}$, Jennifer J. Wolvers ${ }^{5}$, Erik E. Folch ${ }^{13^{*}+}$ and for the NAVIGATE Study Investigators

\begin{abstract}
Background: Electromagnetic navigation bronchoscopy (ENB) is an image-guided, minimally invasive approach that uses a flexible catheter to access pulmonary lesions.

Methods: NAVIGATE is a prospective, multicenter study of the superDimension ${ }^{\mathrm{TM}}$ navigation system. A prespecified 1-month interim analysis of the first 1,000 primary cohort subjects enrolled at 29 sites in the United States and Europe is described. Enrollment and 24-month follow-up are ongoing.

Results: ENB index procedures were conducted for lung lesion biopsy $(n=964)$, fiducial marker placement $(n=210)$, pleural dye marking $(n=17)$, and/or lymph node biopsy $(n=334$; primarily endobronchial ultrasound-guided). Lesions were in the peripheral/middle lung thirds in $92.7 \%, 49.7 \%$ were $<20 \mathrm{~mm}$, and $48.4 \%$ had a bronchus sign. Radial EBUS was used in 54.3\% (543/1,000 subjects) and general anesthesia in 79.7\% (797/1,000). Among the 964 subjects $(1,129$ lesions) undergoing lung lesion biopsy, navigation was completed and tissue was obtained in 94.4\% (910/964). Based on final pathology results, ENB-aided samples were read as malignant in 417/910 (45.8\%) subjects and non-malignant in 372/910 (40.9\%) subjects. An additional 121/910 (13.3\%) were read as inconclusive. One-month follow-up in this interim analysis is not sufficient to calculate the true negative rate or diagnostic yield. Tissue adequacy for genetic testing was $80.0 \%$ (56 of 70 lesions sent for testing). The ENB-related pneumothorax rate was $4.9 \%(49 / 1,000$ ) overall and 3.2\% $(32 / 1,000)$ CTCAE Grade $\geq 2$ (primary endpoint). The ENB-related Grade $\geq 2$ bronchopulmonary hemorrhage and Grade $\geq 4$ respiratory failure rates were 1.0 and $0.6 \%$, respectively.
\end{abstract}

Conclusions: One-month results of the first 1,000 subjects enrolled demonstrate low adverse event rates in a generalizable population across diverse practice settings. Continued enrollment and follow-up are required to calculate the true negative rate and delineate the patient, lesion, and procedural factors contributing to diagnostic yield.

(Continued on next page)

\footnotetext{
*Correspondence: efolch@mgh.harvard.edu

Prior Presentation: Presented at the IASLC 17th World Conference on Lung

Cancer, December 5, 2016: Folch E, Flandes J, Khandhar S. MA05.02

Electromagnetic Navigation Bronchoscopy: A Prospective, Global, Multicenter

Analysis of 1000 Subjects with Lung Lesions. Journal of Thoracic Oncology.

2017;12:S365.

${ }^{\dagger}$ Equal contributors

${ }^{13}$ Division of Pulmonary and Critical Care Medicine, Massachusetts General Hospital, Harvard Medical School, 55 Fruit Street, Bulfinch 148, Boston, MA 02114, USA

Full list of author information is available at the end of the article
} International License (http://creativecommons.org/licenses/by/4.0/), which permits unrestricted use, distribution, and reproduction in any medium, provided you give appropriate credit to the original author(s) and the source, provide a link to the Creative Commons license, and indicate if changes were made. The Creative Commons Public Domain Dedication waiver (http://creativecommons.org/publicdomain/zero/1.0/) applies to the data made available in this article, unless otherwise stated. 
(Continued from previous page)

Trial registration: ClinicalTrials.gov NCT02410837. Registered 31 March 2015.

Keywords: Image-Guided Biopsy, Lung Cancer, Lung Neoplasms, Neoplasm Staging, Solitary Pulmonary Nodule

\section{Background}

Guidelines for lung nodule evaluation recommend the least invasive approach given each patient's clinical presentation [1]. Utilization of electromagnetic navigation bronchoscopy (ENB) has increased over the past ten years as a minimally invasive approach to complement traditional bronchoscopy, endobronchial ultrasound (EBUS), and image-guided transthoracic biopsy. Selection of the most appropriate diagnostic modality based on patient comorbidities and lesion location is critical to provide the fastest, safest, and most complete diagnosis possible.

Seventeen published studies of ENB use have been summarized in three recent meta-analyses [2-4]. Pneumothorax is the most common complication, occurring in approximately $3 \%$ of patients [2], lower than the pooled $20 \%$ rate reported for transthoracic needle biopsy [5]. However, published studies have typically been small, singlecenter, retrospective, and mostly conducted by expert users. The safety, usage profile, and clinical utility of ENB in a large, prospective, multicenter, generalizable population is unknown. The pragmatic design [6] of NAVIGATE maximizes patient eligibility, usual care settings, flexibility of adherence, and a relevant primary outcome for clinical practice. The detailed prospective collection of data also minimizes retrospective bias and allows future multivariate analyses to provide more meaningful information on the variable utilization of this technology into real-world practice and its impact on measurable outcomes, such as diagnostic yield and risk. Furthermore, a heterogeneous dataset will be instructive for the design of potential comparative studies with respect to operator training, subject inclusion criteria, data to be collected, definitions, and expected complication rates.

The primary objectives of this protocol-specified 1,000subject, 1-month interim analysis of the NAVIGATE study [7] are to present the preliminary safety, clinical usage patterns, and performance of ENB in a large, unrestricted, generalizable population across diverse practice settings. The interim data will provide an early look at typical patient and lesion characteristics and procedural standardof-care, generating questions for future NAVIGATE analyses and new clinical studies. Enrollment and continued follow-up are ongoing.

\section{Methods}

NAVIGATE is a prospective, multicenter, global, singlearm, cohort study in subjects undergoing ENB procedures. Enrollment of up to 1,500 subjects is planned at 37 sites in the United States and Europe. Subjects evaluations occur at baseline (within 30 days of the procedure), on the procedure day, and at 1 month, 12 months, and 24 months post-procedure. This manuscript describes the results of a prespecified 1-month interim analysis of the first 1,000 subjects enrolled at 29 sites in the United States and Europe. Enrollment and 12- and 24-month follow-up are ongoing. Brief methods are included below. A full list of study assessments and definitions is included in Additional files 1 and 2. The study design has been published [7].

Inclusion criteria are intentionally broad to ensure external validity. All consecutive, consented adult patients, who are not pregnant or nursing, and who are candidates for an elective ENB procedure based on physician discretion per recommended guidelines and institutional standard-of-care, are eligible. A maximum of 75 subjects is allowed per site. All investigators must have prior ENB experience. Investigators without extensive experience may enroll a maximum of five "roll-in" cases, which are excluded from this interim analysis. Roll-in cases will be included in the 1-year and 2-year analyses of the full enrollment when a more complete evaluation of the impact of user experience on diagnostic yield and other outcomes can be conducted.

All ENB procedures use the superDimension ${ }^{\mathrm{TM}}$ navigation system $[8,9]$ version 6.0 or higher (Medtronic, Minneapolis, $\mathrm{MN}$ ) per product instructions and institutional standard practice. All complementary tools and procedures, including choice of catheter and biopsy tools, order of biopsy tool use, and strategy for staging and diagnostic bronchoscopy were performed at clinician discretion and were captured prospectively for data analysis.

The primary endpoint is pneumothorax related to the ENB index procedure rated Grade $\geq 2$ according to the validated Common Terminology Criteria for Adverse Events (CTCAE) scale [7, 10], as adjudicated by an independent medical monitor. Pneumothorax was protocol-specified as the primary endpoint because it is applicable to all ENB procedures, including lung lesion biopsy, lymph node biopsy, fiducial placement, and pleural dye marking. Major secondary endpoints were all ENB-related pneumothorax, bronchopulmonary hemorrhage, and respiratory failure. Other secondary endpoints reported at 1 month were subject selfreported satisfaction with the procedure; adequacy of samples for molecular testing and mutation type; accurate fiducial placement as assessed by follow-up imaging; 
and success rate of pleural dye marking demonstrated by surgical resection [7].

Diagnostic yield of the ENB index procedure will be calculated at the 12- and 24-month follow-up as the proportion of subjects with a definitive diagnosis (final pathology of the ENB-aided sample). One-month follow-up in this interim analysis is not sufficient to calculate the true negative rate or diagnostic yield. All lung nodules evaluated during the ENB index procedure will be followed for confirmation. Sensitivity, specificity, negative predictive value, and positive predictive value will be published beginning with the 12-month follow-up.

No sample size calculations were conducted for this single-arm, observational study. Analyses were performed using $\mathrm{SAS}^{\circ}$ Version 9.4 (SAS Inc., Cary, NC). Data are summarized by descriptive statistics, including frequency distributions and cross-tabulations for discrete variables and mean, standard deviation, median, minimum, and maximum values for continuous variables. At least $10 \%$ of the data are verified against source files by the sponsor using risk-based monitoring.

\section{Results}

\section{Participants}

This prespecified interim analysis includes the first 1,000 primary cohort subjects enrolled at 29 clinical sites in the United States (27 sites) and Europe (two sites) from April 16, 2015 to June 27, 2016 (Fig. 1, and Additional file 3). Enrollment ranged from 2 to 75 subjects per site. Site types include academic centers (11 sites), private practice (11 sites), and mixed academic/private practice (seven sites). One-month follow-up was completed in 93.3\% of subjects. Chronic obstructive pulmonary disease was present in $44.8 \%$. Approximately one-third of subjects had a history of prior invasive lung procedures (Table 1).

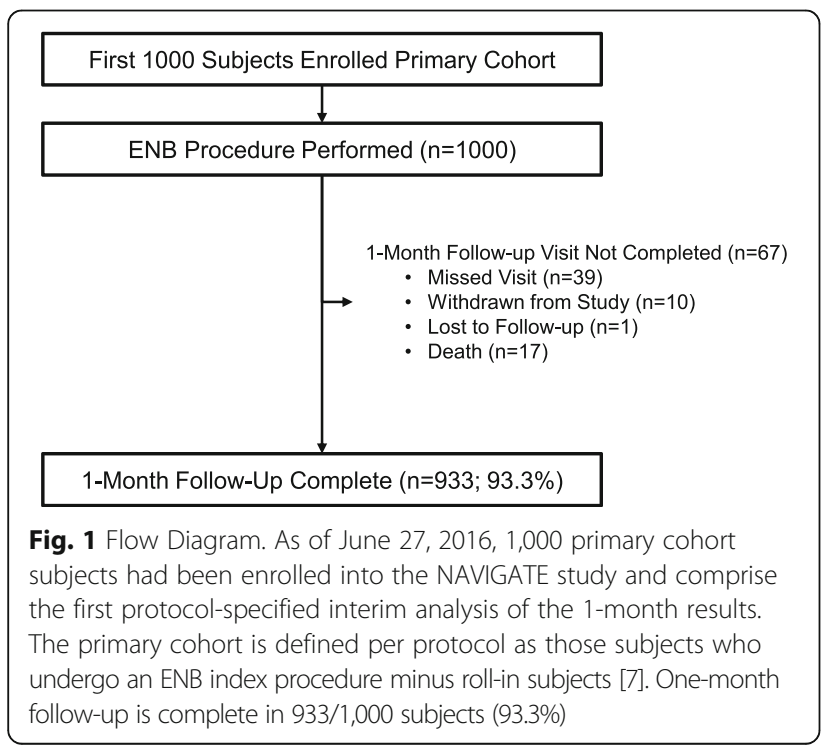

Table 1 Subject demographics (all primary cohort subjects)

\begin{tabular}{|c|c|}
\hline & $N=1000$ Subjects \\
\hline Age at consent (years) & $67.7 \pm 11.3(1000)$ [69.0] (21.0-93.0) \\
\hline Female/Male & $49.1 \% / 50.9 \%$ \\
\hline \multicolumn{2}{|l|}{ Race } \\
\hline White & $85.5 \%(855 / 1000)$ \\
\hline Black or African American & $12.5 \%(125 / 1000)$ \\
\hline Asian & $0.6 \%(6 / 1000)$ \\
\hline American Indian or Alaska Native & $0.4 \%(4 / 1000)$ \\
\hline $\begin{array}{l}\text { Native Hawaiian or Other Pacific } \\
\text { Islander }\end{array}$ & $0.1 \%(1 / 1000)$ \\
\hline Unknown & $0.8 \%(8 / 1000)$ \\
\hline Unable To Report & $0.1 \%(1 / 1000)$ \\
\hline Hispanic or Latino Ethnicity & $4.4 \%(44 / 1000)$ \\
\hline Tobacco History (Current or Former) & $80.8 \%(807 / 999)$ \\
\hline COPD & $44.8 \%(448 / 999)$ \\
\hline $\mathrm{FEV}_{1}$ (\% of predicted) & $74.8 \pm 25.6$ (332) [75.5] (20.0-140.0) \\
\hline $\mathrm{FEV}_{1} /$ FVC Ratio & $0.9 \pm 0.2(331)[0.9](0.3-1.9)$ \\
\hline DLCO (\% of predicted) & $66.4 \pm 24.9$ (225) [66.0] (6.0-141.0) \\
\hline Asthma & $12.6 \%(126 / 999)$ \\
\hline Prior Invasive Lung Procedures ${ }^{a}$ & $30.6 \%(306 / 1000)$ \\
\hline Bronchoscopy & $20.4 \%(204 / 1000)$ \\
\hline Standard Bronchoscopy & $12.3 \%(123 / 1000)$ \\
\hline Image-guided Bronchoscopy ${ }^{b}$ & $9.7 \%(97 / 1000)$ \\
\hline Transthoracic Needle Aspiration & $5.1 \%(51 / 1000)$ \\
\hline Surgery & $11.1 \%(111 / 1000)$ \\
\hline Other & $3.0 \%(30 / 1000)$ \\
\hline Personal History of Cancer & $45.8 \%(458 / 999)$ \\
\hline Family History of Cancer & $61.3 \%(612 / 999)$ \\
\hline $\begin{array}{l}\text { Subject taking Antithrombotic } \\
\text { Medications }{ }^{\mathrm{c}}\end{array}$ & $45.8 \%(458 / 1000)$ \\
\hline Anticoagulant & $10.2 \%(102 / 1000)$ \\
\hline Prescription Antiplatelet & $6.8 \%(68 / 1000)$ \\
\hline Aspirin & $32.5 \%(325 / 1000)$ \\
\hline Other & $1.4 \%(14 / 1000)$ \\
\hline
\end{tabular}

Data are presented as $\mathrm{n} / \mathrm{N}(\%)$ or mean \pm standard deviation (n) [median] (range) Acronyms: COPD chronic obstructive pulmonary disease, DLCO diffusing capacity of the lung for carbon monoxide, FVC forced vital capacity, FEV forced expiratory volume in $1 \mathrm{~s}$, EBUS endobronchial ultrasound, ENB electromagnetic navigation bronchoscopy

${ }^{a}$ Each subject could have multiple prior procedures ${ }^{b}$ Includes $2.3 \%$ (23/1000) standard bronchoscopy with EBUS, 2.8\% (28/1000) superDimension ENB, 2.6\% (26/1000) superDimension ENB with EBUS, $0.8 \%(8 / 1000)$ other navigation bronchoscopy, and $1.8 \%(18 / 1000)$ other navigation bronchoscopy with EBUS

cSubjects could have multiple antithrombotic medications. "Other" includes nonsteroidal anti-inflammatory drugs, fish oil, and vitamins

\section{Procedural characteristics}

One thousand ENB index procedures were conducted in 1,000 subjects. Procedures were conducted for one or more purposes, including lung lesion biopsy $(n=964$ 
subjects), fiducial marker placement $(n=210)$, pleural dye marking $(n=17)$, and/or lymph node biopsy $(n=$ 334; primarily guided by linear EBUS), as shown in Fig. 2. General anesthesia was used in $79.7 \%$ of subjects. Radial EBUS was used during the ENB index procedure in $54.3 \%(543 / 1,000)$ and fluoroscopy was used in $90.1 \%$ $(1,017 / 1,129)$ of lesions. The median ENB procedure time was $25.0 \mathrm{~min}$ (interquartile range 14.0-41.0 $\mathrm{min}$ ). See Table 2 for other procedural characteristics. Overall, $94.8 \%(827 / 872)$ of subjects reported that their expectations for the procedure we adequately met.

\section{Safety}

Pneumothorax CTCAE Grade $\geq 2$ occurred in 32/1,000 subjects (3.2\%; Table 3). Any-grade pneumothorax occurred in 49 subjects (4.9\%). Bronchopulmonary hemorrhage was $1.0 \%$ CTCAE Grade $\geq 2(10 / 1,000)$ and $2.3 \%$ overall $(23 /$ $1,000)$. CTCAE Grade $\geq 4$ respiratory failure occurred in $6 /$ $1,000(0.6 \%)$. As of the 1-month follow-up (which allowed a visit window up to 37 days post-ENB), 23 subjects had died (six completed the 1-month visit; 17 did not). No deaths were considered related to the ENB device or associated tools by either the clinical investigator or the independent medical monitor. There was one procedure-related death due to Grade 5 hypoxic respiratory failure 9 days after the ENB index procedure, deemed related to complications of general anesthesia, in a patient with multiple comorbidities, including cirrhosis, hepatocellular carcinoma, small cell carcinoma, and ovarian cancer.

\section{Lung lesion biopsies}

Among the 964 subjects (1,129 lesions) undergoing lung lesion biopsy, the median lesion size was $20.0 \mathrm{~mm}$ (interquartile range: $16.0 \mathrm{~mm}$ [Q1: 14.0, Q3: 30.0]), and $49.7 \%$ of lesions were $<20 \mathrm{~mm}$ in diameter (Table 4 ). Most lesions were in the peripheral $(62.6 \%)$ or middle $(30.1 \%)$ lung thirds. An airway to the lesion was visible on preprocedure CT (bronchus sign) in $48.4 \%$.

ENB was able to navigate successfully to allow a tissue biopsy (according to subjective operator assessment) in 910 subjects (94.4\%) and 1,036 lesions (91.8\%; Table 5). Rapid on-site evaluation (ROSE) for immediate periprocedural feedback on pathology specimens was conducted in 66.1\% (601/909) of subjects. Among 247 lesions diagnosed with primary lung adenocarcinoma or nonsmall-cell lung cancer not otherwise specified, molecular genetic testing was attempted in $70 / 247$ (28.3\%), with adequate tissue in 56/70 (80.0\%; Table 5).

Based on the final pathology results of the ENB index procedure, tissue was interpreted as malignant in 417/ 910 (45.8\%) subjects (Table 6). Primary lung cancer was diagnosed in $40.1 \%$ of subjects. Preliminary clinical stage [11] in subjects diagnosed with primary lung cancer was 52.9\% Stage I, 10.7\% Stage II, 18.9\% Stage III, and 17.3\% Stage IV (Fig. 3), to be confirmed with follow-up. Lymph node biopsies were attempted during the ENB index procedure (same anesthetic event) in $33.4 \%$ of cases (334/1,000). In 322/334 (96.4\%) of these cases, mediastinal staging was conducted using linear EBUS. Lymph node biopsy was guided by ENB in 42 cases (alone or in combination with linear EBUS).

Based on site-reported assessments of the ENB-aided final pathology sample, tissue was interpreted as nonmalignant in $372 / 910$ (40.9\%) subjects (Table 6). An additional 121/910 (13.3\%) were interpreted as inconclusive. Longer follow-up is required to confirm true

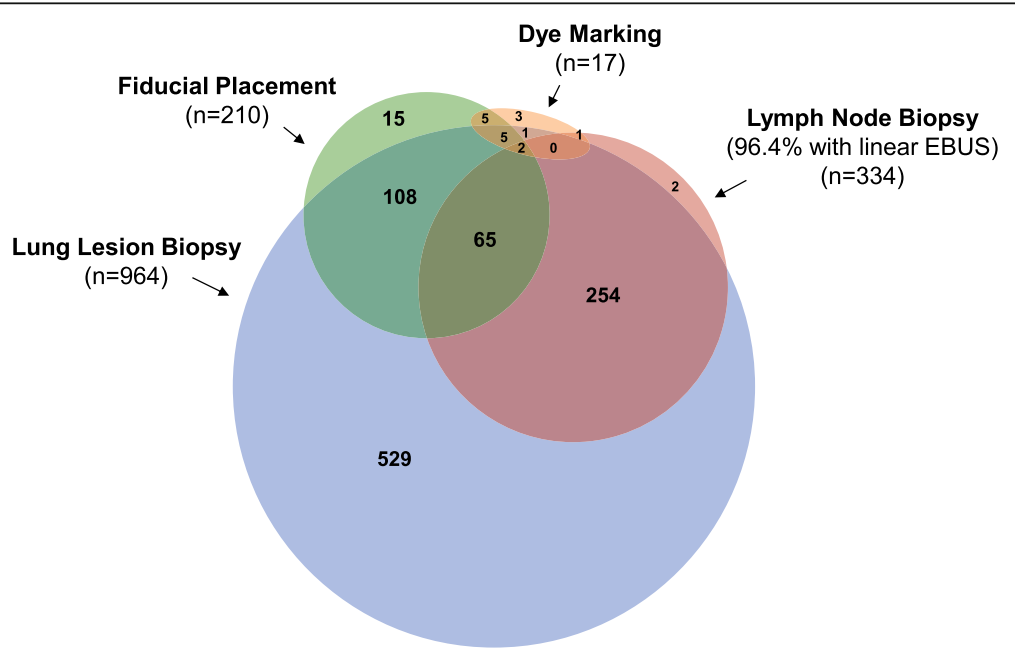

Fig. 2 Reasons for Conducting ENB on a Per Subject Basis. The NAVIGATE ENB index procedure could be conducted for more than one purpose in the same anesthetic event, including lung lesion biopsy, fiducial marker placement, pleural dye marking, or lymph node biopsy. Not drawn to scale. Not shown in graph: ENB-guided fiducial marker placement plus lymph node biopsy $(n=10)$; ENB-guided fiducial marker placement plus lymph node biopsy plus ENB-guided pleural dye marking $(n=0)$ 
Table 2 General procedural characteristics (all primary cohort subjects)

\begin{tabular}{ll}
\hline & $N=1000$ Procedures \\
\hline General Anesthesia & $79.7 \%(797 / 1000)$ \\
Moderate Sedation & $20.3 \%(203 / 1000)$ \\
ENB Software Version & \\
$\quad$ Version 6 & $18.4 \%(184 / 1000)$ \\
$\quad$ Version 7 & $81.6 \%(816 / 1000)$ \\
Radial EBUS used During ENB Procedure ${ }^{a}$ & $54.3 \%(543 / 1000)$ \\
Cone Beam CT used & $5.4 \%(54 / 1000)$ \\
$\begin{array}{l}\text { Total Procedure Time (Bronchoscope In/Out), } \\
\text { min }\end{array}$ & $52.0(36.0[35.0-71.0])$ \\
ENB Procedure Time (Locatable Guide In/Out), & $25.0(27.0[14.0-41.0])$ \\
min ${ }^{b}$ &
\end{tabular}

Data are presented as $\mathrm{n} / \mathrm{N}$ (\%) or median (interquartile range [Q1-Q3]) Acronyms: $C T$ computed tomography, EBUS endobronchial ultrasound, ENB electromagnetic navigation bronchoscopy

aOther than for lymph node biopsy but including all biopsy, fiducial, and pleural dye marking procedures

${ }^{\text {b}}$ Data only available for 499 subjects, because question was added to case report forms after enrollment had begun

versus false negatives and calculate diagnostic yield. At this time, the true prevalence of malignancy in the patient population is unknown.

\section{Fiducial placement and pleural dye marking}

A total of 417 fiducial markers were placed in 210 subjects. Subjective operator assessment of accurate fiducial placement was 208/210 (99.0\%) and fiducial markers were still present at follow-up imaging in 192/205 (93.7\%). In

Table 3 Adverse events related to the ENB index procedure or devices (1 Month Follow-up) ${ }^{\text {a }}$

\begin{tabular}{ll}
\hline & $N=1000$ Subjects \\
\hline Pneumothorax & \\
CTCAE Grade 2 or Higher & $3.2 \%(32 / 1000)$ \\
All Grades & $4.9 \%(49 / 1000)$ \\
Bronchopulmonary Hemorrhage & \\
CTCAE Grade 2 and Higher & $1.0 \%(10 / 1000)$ \\
All Grades & $2.3 \%(23 / 1000)$ \\
Respiratory Failure, CTCAE Grade 4 or Higher & $0.6 \%(6 / 1000)$ \\
$\begin{array}{l}\text { Death (anesthesia-related respiratory failure } 9 \text { days } \\
\text { post-ENB) }\end{array}$ & $0.1 \%(1 / 1000)$ \\
\hline
\end{tabular}

Data are presented as $\%$ ( $\mathrm{n} / \mathrm{N}$ subjects)

Acronyms: CTCAE Common Terminology Criteria for Adverse Events, ENB electromagnetic navigation bronchoscopy

${ }^{a}$ Other than expected observations associated with anesthesia (e.g., common or expected post-procedure pain, transient nausea, transient emesis, post-procedure constipation)

${ }^{b}$ Grade 5 hypoxic respiratory failure 9 days after the ENB index procedure, deemed related to complications of general anesthesia, in a patient with multiple comorbidities, including cirrhosis, hepatocellular carcinoma, small cell carcinoma, and ovarian cancer. As of 1-month follow-up, a total of 23 subjects had died (6 completed 1-month follow-up visit; 17 did not). As of the 1-month follow-up, no other deaths were considered related to the ENB device or associated tools by either the clinical investigator or the independent medical monitor
Table 4 Lung lesion characteristics (subjects undergoing ENBaided biopsy)

\begin{tabular}{|c|c|}
\hline & $\begin{array}{l}N=1129 \text { Lesions in } 964 \\
\text { Subjects }\end{array}$ \\
\hline $\begin{array}{l}\text { Pre-test probability of malignancy } \\
\text { (physician estimation) }\end{array}$ & $\begin{array}{l}67.1 \pm 26.5(790)[75.0] \\
(0.0-100.0)\end{array}$ \\
\hline $\begin{array}{l}\text { Pre-test probability of malignancy } \\
\text { (Swenson's equation) }^{a}\end{array}$ & $\begin{array}{l}61.6 \pm 29.4(789)[67.1] \\
(2.9-100.0)\end{array}$ \\
\hline \multicolumn{2}{|l|}{ Average Lung Lesion Size, mm } \\
\hline Mean $\pm S D(N)$ & $23.6 \pm 14.4(1129)$ \\
\hline Median, Range (min-max) & $20.0(3.0-118.0)$ \\
\hline Interquartile Range (Q1-Q3) & $16.0(14.0-30.0)$ \\
\hline$<20 \mathrm{~mm}$ & $49.7 \%(561 / 1129)$ \\
\hline$\geq 20 \mathrm{~mm}$ & $50.3 \%(568 / 1129)$ \\
\hline \multicolumn{2}{|l|}{ Lesion Location } \\
\hline Right Upper Lobe & $31.7 \%(358 / 1129)$ \\
\hline Right Middle Lobe & $8.1 \%(91 / 1129)$ \\
\hline Right Lower Lobe & $19.0 \%(215 / 1129)$ \\
\hline Left Upper Lobe & $25.9 \%(292 / 1129)$ \\
\hline Left Lower Lobe & $15.3 \%(173 / 1129)$ \\
\hline \multicolumn{2}{|l|}{ Lung Zone ${ }^{b}$} \\
\hline Peripheral third of lung on $\mathrm{CT}$ & $62.6 \%(707 / 1129)$ \\
\hline Middle third of lung on $\mathrm{CT}$ & $30.1 \%(340 / 1129)$ \\
\hline Proximal third of lung on $\mathrm{CT}$ & $7.3 \%(82 / 1129)$ \\
\hline Lesion Visible on Fluoroscopy & $60.0 \%(610 / 1017)$ \\
\hline $\begin{array}{l}\text { Ground Glass Lesions (Suzuki } \\
\text { Class } 1 \text { or 2) [28] }\end{array}$ & $6.3 \%(71 / 1123)$ \\
\hline Spiculated Lesion Border & $60.9 \%(687 / 1128)$ \\
\hline Bronchus Sign Present on CT & $48.4 \%(546 / 1129)$ \\
\hline $\begin{array}{l}\text { Lesion PET Positive ( } \geq 2.5 \text { standard } \\
\text { uptake value) }\end{array}$ & $80.9 \%(479 / 592)$ \\
\hline
\end{tabular}

Data are presented as $n / N(\%)$ or mean \pm standard deviation $(n)$ [median] (range)

Acronyms: CT computed tomography, PET positron emission tomography, SD standard deviation

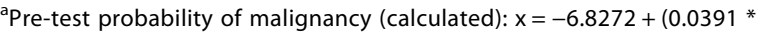
"age" $)+(0.7917 *$ "tobacco history" $)+(1.3388 *$ "history of extrathoracic cancer") $+\left(0.1274\right.$ * "diameter in $\left.\mathrm{mm}^{\prime \prime}\right)+(1.0407$ * "spiculation") $+(0.7838$ * "upper lobe"). Not applicable to patients with a diagnosis of cancer that has been made within the previous 5 years or to patients with previous lung cancer [29]

${ }^{\mathrm{b}}$ See Folch et al. 2016 for definitions [7]

subjects undergoing fiducial marker placement, ENBrelated adverse events included eight pneumothoraces CTCAE Grade $\geq 2(3.8 \%)$, three respiratory failures CTCAE Grade $\geq 4$ (1.4\%), and one bronchopulmonary hemorrhage Grade 1. Pleural dye marking was conducted in 17 subjects, of which 15 (88.2\%) were considered adequate for surgical resection.

\section{Discussion}

Lung cancer causes one quarter of all cancer deaths, representing a significant public health problem [12]. 
Table 5 Procedural characteristics in lung lesion biopsy cases

\begin{tabular}{|c|c|}
\hline & $\begin{array}{l}N=1129 \text { Lesions in } 964 \\
\text { Subjects }\end{array}$ \\
\hline$\overline{\text { Navigation Success (per lesion) }{ }^{a}}$ & $91.8 \%(1036 / 1129)$ \\
\hline Navigation Success (per subject) ${ }^{a}$ & $94.4 \%(910 / 964)$ \\
\hline Number of Lesions Biopsied (per subject) & $1.2 \pm 0.5(964)[1.0](1.0-5.0)$ \\
\hline \multicolumn{2}{|c|}{ Biopsy Tools Used During ENB Index Procedure ${ }^{b}$} \\
\hline Aspiration Needle & $52.2 \%(503 / 964)$ \\
\hline Biopsy Forceps & $81.2 \%(783 / 964)$ \\
\hline Cytology Brush & $47.0 \%(453 / 964)$ \\
\hline Needle-Tipped Cytology Brush & $20.2 \%(195 / 964)$ \\
\hline Triple Needle-Tipped Cytology Brush & $23.4 \%(226 / 964)$ \\
\hline GenCut $^{\text {TM }}$ Core Biopsy Tool & $18.9 \%(182 / 964)$ \\
\hline Bronchoalveolar Lavage or Washing & $37.8 \%(364 / 964)$ \\
\hline Rapid on-site evaluation (ROSE) used ${ }^{c}$ & $66.1 \%(601 / 909)$ \\
\hline Molecular/genetic testing attempted ${ }^{d}$ & $28.3 \%(70 / 247)$ \\
\hline Molecular/genetic testing successful & $80.0 \%(56 / 70)$ \\
\hline Inadequate Sample & $20.0 \%(14 / 70)$ \\
\hline Molecular/genetic testing not attempted ${ }^{\mathrm{d}}$ & $71.7 \%(177 / 247)$ \\
\hline Not Necessary & $49.2 \%(87 / 177)$ \\
\hline Not Standard Practice & $41.2 \%(73 / 177)$ \\
\hline Other & $9.6 \%(17 / 177)$ \\
\hline
\end{tabular}

Data are presented as $\mathrm{n} / \mathrm{N}(\%)$ or mean \pm standard deviation ( $\mathrm{n}$ [ [median] (range) ${ }^{a}$ Able to navigate successfully and allow a tissue biopsy (according to subjective operator assessment)

${ }^{\mathrm{b}}$ More than one tool used per procedure

${ }^{C}$ Per subject, among subjects with an ENB-aided tissue sample obtained. Data missing for 1 subject

${ }^{\mathrm{d}}$ Per lesion, among 247 lesions with primary adenocarcinoma $(n=233)$ or primary non-small-cell lung cancer not otherwise specified $(n=14)$. More than one reason could be chosen per lesion

While the incidence has declined in concert with decreased smoking prevalence, survival rates have improved little over the past 50-60 years, largely due to a high proportion of late-stage diagnoses with a 5 -year survival rate of only $4 \%$ [12]. Earlier-stage diagnoses will lead to more meaningful improvements in survival and will require modalities that allow the accurate sampling of smaller, more peripheral lung lesions. The National Lung Screening Trial [13] and screening coverage in select high-risk patients [14] has been projected to increase low-dose CT utilization by over ten million procedures annually [15]. However, an extremely high percentage (96\%) of false positive screening results $[13,16]$ and the risk of unnecessary procedures requires the judicious use of minimally invasive options and a careful balance of the risk-to-benefit ratio for further diagnosis and management [17].

Several current technologies can provide minimally invasive diagnostic evaluation in appropriately selected patients, although each has limitations. PET-CT is often considered the second-line diagnostic option for nodules detected on CT [18], but is typically not reimbursed for
Table 6 Pathology result aided by the index ENB procedure ${ }^{a}$

\begin{tabular}{|c|c|}
\hline \multicolumn{2}{|c|}{$N=910$ subjects with navigation complete and tissue sample obtained } \\
\hline Malignant & $45.8 \%(417 / 910)$ \\
\hline Lung cancer & $40.1 \%(365 / 910)$ \\
\hline Non-Small Cell Lung Cancer (NSCLC) & $36.4 \%(331 / 910)$ \\
\hline Adenocarcinoma & $23.5 \%(214 / 910)$ \\
\hline Squamous Carcinoma & $11.4 \%(104 / 910)$ \\
\hline Other NSCLC & $1.5 \%(14 / 910)$ \\
\hline Small Cell Carcinoma & $2.9 \%(26 / 910)$ \\
\hline Neuroendocrine Carcinoma & $1.1 \%(10 / 910)$ \\
\hline Metastatic Carcinoma of Extrathoracic Origin & $4.4 \%(40 / 910)$ \\
\hline Lymphoma & $0.2 \%(2 / 910)$ \\
\hline Malignant Cells (unable to characterize) & $0.9 \%(8 / 910)$ \\
\hline Other & $0.3 \%(3 / 910)$ \\
\hline \multicolumn{2}{|l|}{ Site-Reported Non-Malignant or Inconclusive Results } \\
\hline Non-Malignant & $40.9 \%(372 / 910)$ \\
\hline Normal Lung Tissue/Bronchial Epithelium & $10.4 \%(95 / 910)$ \\
\hline Benign Non-Specific & $21.9 \%(199 / 910)$ \\
\hline Benign Inflammation & $15.3 \%(139 / 910)$ \\
\hline Other ${ }^{b}$ & $6.7 \%(61 / 910)$ \\
\hline Infection & $2.9 \%(26 / 910)$ \\
\hline Bacterial & $1.8 \%(16 / 910)$ \\
\hline Fungal & $0.9 \%(8 / 910)$ \\
\hline Viral & $0.2 \%(2 / 910)$ \\
\hline Granuloma & $1.4 \%(13 / 910)$ \\
\hline Atypical Cells & $1.9 \%(17 / 910)$ \\
\hline Lymphocytes & $1.1 \%(10 / 910)$ \\
\hline Organizing Pneumonia & $0.8 \%(7 / 910)$ \\
\hline Interstitial Lung Disease & $0.4 \%(4 / 910)$ \\
\hline Other & $1.0 \%(9 / 910)$ \\
\hline Inconclusive & $13.3 \%(121 / 910)$ \\
\hline
\end{tabular}

Data are presented as $\mathrm{n} / \mathrm{N}(\%)$ or mean \pm standard deviation (n) (range) Acronym: $E N B$ electromagnetic navigation bronchoscopy

apreliminary 1-month results, to be confirmed by subsequent surgery, biopsy, or radiographic follow-up through 2 years as appropriate per clinician's assessment of the patient's probability of malignancy. One-month follow-up in this interim analysis is not sufficient to calculate the true negative rate or diagnostic yield

"Includes reactive bronchial cells and other nonspecific "benign" diagnoses 'Reported as 1 case each of: (1) fibroelastic scar, (2) squamous dysplasia, (3) squamous metaplasia, (4) radiotherapy changes, (5) blood clots post-FNA, (6) asbestos fibrosis, (7) benign metastasizing leiomyoma, (8) focally anthracotic alveolated pulmonary parenchyma, and (9) iron pill aspiration

screening and does not provide tissue diagnosis. Conventional bronchoscopy is safe but is limited to proximal lesions and has a high non-diagnostic rate, potentially leading to unnecessary invasive procedures in $20-25 \%$ of patients, including the use of thoracoscopy for diagnostic wedge resection [19-21]. Image-guided transthoracic biopsy provides high diagnostic accuracy but at the cost of pneumothorax rates averaging 20\% (range 4 to $62 \%$ ) 


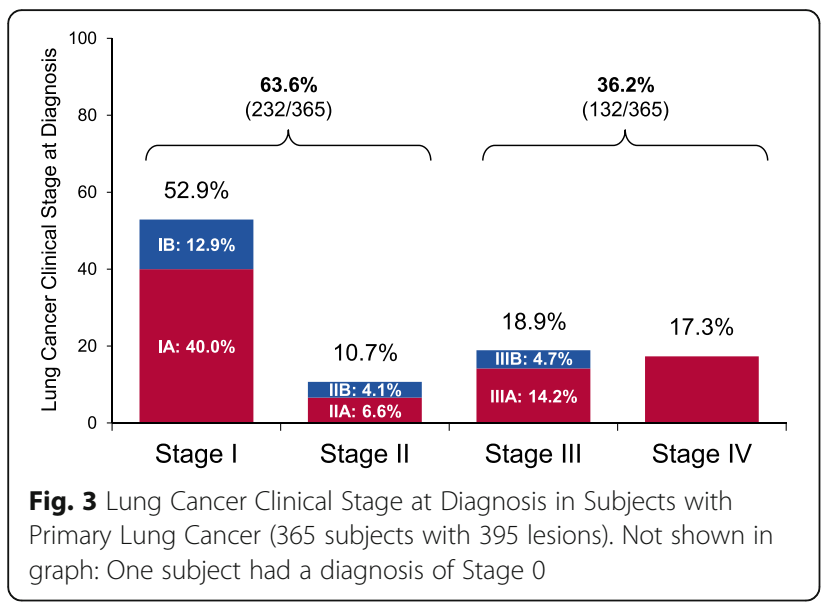

[5] and the need for additional procedures to diagnose and stage mediastinal lymph nodes. ENB provides a minimally invasive platform for peripheral lung lesion sampling, concurrent lymph node staging with linear EBUS, preparation for treatment via fiducial placement or localization via pleural dye marking in a single procedure.

The primary objective of this interim NAVIGATE analysis was to evaluate ENB safety. While published pneumothorax rates are low (3.1\% [range 0-13\%]) [2], most prior studies are single-center with fewer than 100 subjects [4, 7]. The current analysis demonstrates low pneumothorax, bronchopulmonary hemorrhage, and respiratory failure rates in the context of a large, diverse study cohort and a wide range of user experience levels, confirming the safety of advanced bronchoscopy for the access and sampling of all pulmonary nodules. Pneumothorax was also infrequent following fiducial placement (3.8\%), in contrast to rates ranging from 22 to $67 \%$ following percutaneous fiducial marking [22], Despite the advanced stage of some of the enrolled subjects, there were only 23 deaths within the 1-month follow-up timeframe, further substantiating the safety of the procedure. Only one death was considered related to the ENB index procedure, due to general anesthesia in a patient with multiple comorbidities, and none were related to the ENB device or associated tools. These results suggest a highly favorable risk-to-benefit ratio for the use of ENB to aid in lung lesion biopsies, particularly given the risk profile of the patients included, with approximately $45 \%$ COPD incidence and a relatively high rate of Stage III-IV disease.

A second objective of this analysis was to explore the real-world usage patterns and clinical utility of ENB. The interim results elucidate the rates of general anesthesia use (79.7\%), ROSE utilization (66.1\%), and concurrent fluoroscopic (90.1\%) and radial EBUS (54.3\%) guidance. Of note, nearly half of ENB index procedures were conducted for multiple purposes, including $33.4 \%$ with lymph node staging (primarily EBUS-guided) and $21.0 \%$ with fiducial markers placed. Tissue adequacy for molecular genetic testing was also high $(80.0 \%)$ and similar to prior studies [23]. These results suggest that, in unrestricted practice settings, ENB is used to diagnose peripheral lung nodules and perform concurrent linear EBUS-guided mediastinal lymph node staging in a single anesthetic event, facilitating a multidisciplinary, comprehensive patient care approach.

A third objective of this interim analysis was to provide a preliminary look at ENB performance. From a patient perspective, all important follow-up cadence and treatment decisions are made within the 30-day window after the diagnostic procedure. At the 1-month time-point, ENB provided a preliminary malignant diagnosis in $45.8 \%$ of subjects, including $40.1 \%$ with lung cancer. The initial $45.8 \%$ malignancy rate in NAVIGATE is consistent with other recent ENB publications reporting malignancy rates of $35-60 \%$ [24-27], and is expectedly higher than the $3.7 \%$ positive malignancy rate seen in the National Lung Screening Trial [13].

One-month follow-up is not sufficient to calculate the true versus false negative rate or diagnostic yield, as the true prevalence of lung cancer in this population is unknown at this time. All non-malignant pathology findings require confirmation with longer-term follow-up or additional diagnostic procedures, depending upon the pretest probability of malignancy and in accordance with society guidelines $[1,18]$. All follow-up procedures and final diagnoses will be captured and reported. Early indicators of clinical stage in NAVIGATE subjects diagnosed with lung cancer also suggest a $64 \%$ rate of Stage I-II diagnoses, which are more amenable to surgical intervention for curative intent. In this observational study with consecutive enrollment, approximately $36 \%$ of NAVIGATE subjects had Stage III-IV lung cancer. Diagnostic testing of late-stage patients in NAVIGATE may reflect not only a lack of standardization for patient selection but also the changing landscape of personalized medicine and treatment options for Stage III-IV disease. Patient selection for ENB, as well as multivariate predictors of safety and effectiveness, will be explored in future NAVIGATE analyses of the full cohort. This will include an analysis of Stage III-IV cases to explore the patient, lesion, and operator/center factors leading to the inclusion of these cases in the study.

The final objective of this preliminary analysis was to generate questions for future NAVIGATE analyses and comparative studies. Unexpected observations included a high percentage of lesions without a CT bronchus sign (52\%) and a relatively low proportion of subjects in whom genetic testing was attempted (28\%). While current guidelines recommend genetic testing for only late-stage disease, there is extensive variation between institutions. Tissue requirements for comprehensive molecular testing and the practice of personalized medicine will continue to evolve. 
Future analyses will describe molecular genetic evaluation in the NAVIGATE cohort in more detail. Other future questions include multivariate predictors of safety and diagnostic yield, factors affecting the need for concurrent radial EBUS or other fluoroscopic guidance, usage patterns of fiducial and pleural dye marking, success rates of various biopsy tools, and cost effectiveness. In this way, NAVIGATE will help to set the benchmark for the ideal ENB patient, and define the procedural techniques contributing to enhanced performance. Whether ENB truly enables a shift to an earlier stage diagnosis, and the impact on long-term patient survival, healthcare utilization, and costs, will also be topics for future NAVIGATE analyses.

\section{Limitations}

This is a nonrandomized, single-arm analysis of 1-month interim results. Longer-term follow-up is required to determine the accuracy of ENB-aided diagnoses, and calculate diagnostic yield. Follow-up through 24 months is in progress. This analysis also evaluates only one navigational bronchoscopy system; other systems are currently available for clinical use.

\section{Conclusions}

This early look at the NAVIGATE results provides information about usage patterns and utility of ENB in a large, unrestricted, generalizable population across diverse practice settings. In the first 1,000 subjects enrolled, 1-month follow-up demonstrates low adverse event rates among a heterogeneous cohort. Continued enrollment and followup will demonstrate the negative predictive value and delineate the patient, lesion, and procedural characteristics contributing to diagnostic yield. This preliminary analysis generates questions to be explored in future controlled clinical studies. Further follow-up will also help define objective endpoints to guide future population-based guidelines for intervention.

\section{Additional files}

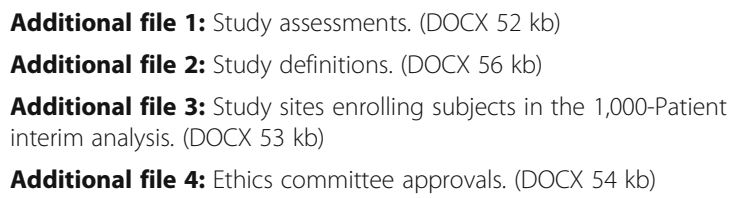

\section{Abbreviations}

CT: Computed tomography; CTCAE: Common Terminology Criteria for Adverse Events; EBUS: Endobronchial ultrasound; ENB: Electromagnetic navigation bronchoscopy; PET: Positron-emission tomography;

TTNA: Transthoracic needle aspiration

\section{Acknowledgements}

The study is sponsored and funded by Medtronic (Minneapolis, MN). Medical writing support was provided by Kristin L. Hood PhD, a full-time employee of Medtronic and coauthor on this paper. The authors wish to thank Haiying Lin (Medtronic) for biostatistics support. The authors also wish to thank the investigators and staff of all participating clinical sites (see Additional file 3).

\section{Funding}

The study is sponsored and funded by Medtronic (Minneapolis, MN), which contributed to the study design, data collection, and data analysis, and assisted with manuscript writing. The lead authors (EF and SK) had full access to all study data and final responsibility for the decision to submit for publication.

\section{Availability of data and materials}

The NAVIGATE dataset will be made publicly available on ClinicalTrials.gov (NCT02410837) after the completion of study enrollment and follow-up. The interim data on which this paper is based are available from the corresponding author on reasonable request.

\section{Authors' contributions}

All authors made substantial contributions to all aspects of the study conduct and manuscript development beginning with the initial study conception, including study design (SJK, MRB, TRG, KLH, WSK, SDM, MP, EMT, MMW, EEF), data acquisition (MRB, JF, TRG, WSK, DJM, SDM, MP, MMW), data analysis (SJK, KLH, JJW, EEF), data interpretation (SJK, MRB, TRG, SDM, MMW, EEF), manuscript writing (SJK, KLH, EEF), critical revisions (all authors), final approval of the manuscript for submission (all authors); and agreement to be accountable for the accuracy and integrity of the work (all authors).

\section{Competing interests}

Financial disclosures related to the submitted work: SJK, MRB, TRG, WSK, SDM, EMT, MMW, and EEF serve on the Clinical Advisory Board for Medtronic and received travel funds and fees for participation; SJK, JF, DJM, SDM, and EEF serve on the NAVIGATE Steering Committee and have received fees for participation; KLH and JJW are full-time employees and stockholders of Medtronic, MMW received consulting fees from Medtronic. Financial disclosures outside the submitted work: MRB and MP received consulting fees from Medtronic; $\mathrm{KLH}$ is a stockholder of Boston Scientific; WSK is a part-time employee of Medtronic (employment began after study enrollment was complete) and has received consulting fees from Medtronic with intellectual property rights; SDM received consulting fees from Boston Scientific, Olympus, Concordia, and Auris Robotics; EMT received travel funds and honoraria from Medtronic as a member of their Speakers' Bureau; EEF is on the Scientific Advisory board for Boston Scientific and the Education Advisory Board for Olympus.

\section{Consent for publication}

Not applicable. This paper presents aggregate data.

\section{Ethics approval and consent to participate}

This study is being conducted in accordance with the Declaration of Helsinki and all local regulatory requirements. The protocol was approved by the institutional review board of all participating clinical sites (see Additional file 4), and all subjects provided written informed consent prior to participation.

\section{Publisher's Note}

Springer Nature remains neutral with regard to jurisdictional claims in published maps and institutional affiliations.

\footnotetext{
Author details

${ }^{1}$ Inova Health System, Fairfax Hospital, Falls Church, VA, USA. ${ }^{2}$ East Carolina University, Greenville, NC, USA. ${ }^{3}$ Pulmonary Department, IIS-Fundacion Jimenez Diaz University Hospital, CIBERES, Madrid, Spain. ${ }^{4}$ Department of Pulmonary, Allergy, and Critical Care Medicine and Transplant Center, Cleveland Clinic, Cleveland, OH, USA. ${ }^{5}$ Medtronic, Minneapolis, MN, USA. ${ }^{6}$ Pulmonary and Critical Care Associates of Baltimore, Baltimore, MD, USA. ${ }^{7}$ Division of Cardiothoracic Surgery, University of Alabama at Birmingham, Birmingham, AL, USA. ${ }^{8}$ Interventional Pulmonology Fellowship Program, The University of Chicago Medicine, Chicago, IL, USA. ${ }^{9}$ Pulmonary Department, Pinehurst Medical Clinic and FirstHealth Moore Regional Hospital, Pinehurst, NC, USA. ${ }^{10}$ Department of Thoracic Oncology, Moffitt Cancer Center, Tampa, FL, USA. ${ }^{11}$ Department of Surgery and Department of Oncologic Sciences, University of South Florida Morsani College of Medicine, Tampa, FL, USA. ${ }^{12}$ Department of Medicine, Duke University Medical Center, Durham, NC, USA. ${ }^{13}$ Division of Pulmonary and Critical Care Medicine, Massachusetts
} 
General Hospital, Harvard Medical School, 55 Fruit Street, Bulfinch 148, Boston, MA 02114, USA. ${ }^{14}$ Present Address: Princeton Baptist Medical Center, Birmingham, AL, USA.

Received: 25 January 2017 Accepted: 28 March 2017

Published online: 11 April 2017

\section{References}

1. Rivera MP, Mehta AC, Wahidi MM. Establishing the diagnosis of lung cancer: Diagnosis and management of lung cancer, 3rd ed: American College of Chest Physicians evidence-based clinical practice guidelines. Chest. 2013; 143:e142S-65.

2. Gex G, Pralong JA, Combescure C, Seijo L, Rochat T, Soccal PM. Diagnostic yield and safety of electromagnetic navigation bronchoscopy for lung nodules: a systematic review and meta-analysis. Respiration. 2014;87:165-76.

3. Wang Memoli JS, Nietert PJ, Silvestri GA. Meta-analysis of guided bronchoscopy for the evaluation of the pulmonary nodule. Chest. 2012;142:385-93.

4. Zhang W, Chen S, Dong X, Lei P. Meta-analysis of the diagnostic yield and safety of electromagnetic navigation bronchoscopy for lung nodules. J Thorac Dis. 2015:7:799-809.

5. DiBardino DM, Yarmus LB, Semaan RW. Transthoracic needle biopsy of the lung. J Thorac Dis. 2015;7:S304-16.

6. Ford I, Norrie J. Pragmatic Trials. N Engl J Med. 2016;375:454-63.

7. Folch EE, Bowling MR, Gildea TR, Hood KL, Murgu SD, Toloza EM, et al. Design of a prospective, multicenter, global, cohort study of electromagnetic navigation bronchoscopy. BMC Pulm Med. 2016:16:60.

8. Reynisson PJ, Leira HO, Hernes TN, Hofstad EF, Scali M, Sorger H, et al. Navigated bronchoscopy: a technical review. J Bronchology Interv Pulmonol. 2014;21:242-64

9. Seijo L. Electromagnetic navigation bronchoscopy: clinical utility in the diagnosis of lung cancer. Lung Cancer. 2016;7:111-8.

10. National Cancer Institute, Cancer Therapy Evaluation Program, United States Department of Health and Human Services, National Institutes of Health. Common Terminology Criteria for Adverse Events (CTCAE) Version 4.0. http://ctep.cancer.gov/protocolDevelopment/electronic_applications/ctc htm\#ctc_40. Accessed 16 Dec 2016

11. Hari DM, Leung AM, Lee JH, Sim MS, Vuong B, Chiu CG, et al. AJCC Cancer Staging Manual 7th edition criteria for colon cancer: do the complex modifications improve prognostic assessment? J Am Coll Surg. 2013;217:181-90.

12. Siegel RL, Miller KD, Jemal A. Cancer statistics, 2016. CA Cancer J Clin. 2016; 66:7-30.

13. Aberle DR, Adams AM, Berg CD, Black WC, Clapp JD, Fagerstrom RM, et al. Reduced lung-cancer mortality with low-dose computed tomographic screening. N Engl J Med. 2011;365:395-409.

14. Centers for Medicare \& Medicaid Services, United States Department of Health and Human Services. Decision Memo for Screening for Lung Cancer with Low Dose Computed Tomography (LDCT) (CAG-00439 N, 5 Feb 2015). https://www.cms.gov/medicare-coverage-database/details/nca-decisionmemo.aspx?NCAld=274. Accessed 16 Dec 2016.

15. Roth JA, Sullivan SD, Goulart BH, Ravelo A, Sanderson JC, Ramsey SD. Projected Clinical, Resource Use, and Fiscal Impacts of Implementing LowDose Computed Tomography Lung Cancer Screening in Medicare. J Oncol Pract. 2015;11:267-72.

16. McWilliams A, Tammemagi MC, Mayo JR, Roberts H, Liu G, Soghrati K, et al. Probability of cancer in pulmonary nodules detected on first screening $\mathrm{CT}$. N Engl J Med. 2013;369:910-9.

17. Tanoue LT, Tanner NT, Gould MK, Silvestri GA. Lung cancer screening. Am J Respir Crit Care Med. 2015;191:19-33.

18. Gould MK, Donington J, Lynch WR, Mazzone PJ, Midthun DE, Naidich DP, et al. Evaluation of individuals with pulmonary nodules: when is it lung cancer? Diagnosis and management of lung cancer, 3rd ed: American College of Chest Physicians evidence-based clinical practice guidelines. Chest. 2013:143:e93S-120.

19. Silvestri GA, Vachani A, Whitney D, Elashoff M, Porta Smith K, Ferguson JS, et al. A Bronchial Genomic Classifier for the Diagnostic Evaluation of Lung Cancer. N Engl J Med. 2015;373:243-51.

20. Detterbeck FC, Mazzone PJ, Naidich DP, Bach PB. Screening for lung cancer: Diagnosis and management of lung cancer, 3rd ed: American College of Chest Physicians evidence-based clinical practice guidelines. Chest. 2013; 143:e78S-92.
21. Grogan EL, Weinstein JJ, Deppen SA, Putnam Jr JB, Nesbitt JC, Lambright ES, et al. Thoracic operations for pulmonary nodules are frequently not futile in patients with benign disease. J Thorac Oncol. 2011;6:1720-5.

22. Hagmeyer L, Priegnitz C, Kocher M, Schilcher B, Budach W, Treml M, et al. Fiducial marker placement via conventional or electromagnetic navigation bronchoscopy (ENB): an interdisciplinary approach to the curative management of lung cancer. Clin Respir J. 2016;10:291-7.

23. Vanderlaan PA, Yamaguchi N, Folch E, Boucher DH, Kent MS, Gangadharan SP, et al. Success and failure rates of tumor genotyping techniques in routine pathological samples with non-small-cell lung cancer. Lung Cancer. 2014;84:39-44.

24. Loo FL, Halligan AM, Port JL, Hoda RS. The emerging technique of electromagnetic navigation bronchoscopy-guided fine-needle aspiration of peripheral lung lesions: promising results in 50 lesions. Cancer Cytopathol. 2014;122:191-9.

25. Odronic SI, Gildea TR, Chute DJ. Electromagnetic navigation bronchoscopyguided fine needle aspiration for the diagnosis of lung lesions. Diagn Cytopathol. 2014;42:1045-50

26. Garwood SK, ClenDening P, Hevelone ND, Hood KL, Pidgeon S, Wudel LJ. Navigational bronchoscopy at a community hospital: clinical and economic outcomes. Lung Cancer Manag. 2016;5:131-40.

27. Bowling MR, Kohan MW, Walker P, Efird J, Ben OS. The effect of general anesthesia versus intravenous sedation on diagnostic yield and success in electromagnetic navigation bronchoscopy. J Bronchology Interv Pulmonol. 2015;22:5-13.

28. Suzuki K, Kusumoto M, Watanabe S, Tsuchiya R, Asamura H. Radiologic classification of small adenocarcinoma of the lung: radiologic-pathologic correlation and its prognostic impact. Ann Thorac Surg. 2006;81:413-9.

29. Swensen SJ, Silverstein MD, Ilstrup DM, Schleck CD, Edell ES. The probability of malignancy in solitary pulmonary nodules. Application to small radiologically indeterminate nodules. Arch Intern Med. 1997;157:849-55.

\section{Submit your next manuscript to BioMed Central and we will help you at every step:}

- We accept pre-submission inquiries

- Our selector tool helps you to find the most relevant journal

- We provide round the clock customer support

- Convenient online submission

- Thorough peer review

- Inclusion in PubMed and all major indexing services

- Maximum visibility for your research

Submit your manuscript at www.biomedcentral.com/submit
C) Biomed Central 